\title{
EVALUASI KINERJA DAN PENGEMBANGAN PENGOLAHAN INSTALASI PENGOLAH AIR LIMBAH (IPAL) MOJOSONGO
}

\author{
Fatayah N U1), Budi Utomo'), Sudarto ${ }^{3)}$ \\ 1) Mahasiswa Program Studi Teknik Sipil Universitas Sebelas Maret \\ 2) Dosen Program Studi Teknik Sipil Universitas Sebelas Maret \\ 3) Dosen Program Studi Teknik Sipil Universitas Sebelas Maret \\ Jalan Ir. Sutami No.36A Surakarta 57126.Telp: (0271)647069 \\ Email : fatayahnu@gmail.com
}

\begin{abstract}
Mojosongo wastewater treatment plant (WWTP) is a domestic wastewater treatplant unit in Surakarta, where is located in Mojosongo and serves Mojosongo, Nusukan, and Kadipiro areas. The wastewater treatment is done by the regional water company of Surakarta with the development capacity of processing is $50 \mathrm{~L} / \mathrm{s}$ since 2011 and has served 5,425 bome connections from active customers by 2015. The purposes of this research are to evaluate the existing performance and to predict the quantitative performance of input discharge at Mojosongo WWTP based on the projected of population growth and the number of wastewater customers in the service area by the next 20 years. Alternative development of wastewater treatment is also given as one of long-term solution in domestic wastewater management concept in Surakarta. The result of research analysis shows that the performance of Mojosongo WWTP in quantitative term based on the wastewater discharge flowing from 5,425 home connections is $31 \mathrm{~L} / \mathrm{s}$, while in qualitative term based on the value of processing efficiency of the wastewater quality tests are $71,31 \%$ BOD 5 efficiency and 60,83\% COD efficiency. Quantitative performance prediction by input discharge of Mojosongo WWTP over the next 20 years based on the population is $149 \mathrm{~L} / \mathrm{s}$ and based on the number of customers is 50 $L / s$. Alternative development of wastewater treatment as a long-term solutions are focused on the main processing of WWTP, which is aeration unit, by changing the residence time, changing the processing system to parallel, and increasing the number of aerator usage.
\end{abstract}

Keyword : Mojosongo, WWTP, discharge, population, customers

\begin{abstract}
Abstrak
IPAL Mojosongo adalah unit pengolah air limbah rumah tangga di Kota Surakarta yang berlokasi di Kelurahan Mojosongo dan melayani wilayah Mojosongo, Nusukan, dan Kadipiro. Pengolahan air limbah di IPAL Mojosongo dilakukan oleh PDAM Kota Surakarta dengan pengembangan kapasitas pengolahan sebesar $50 \mathrm{~L} /$ detik sejak tahun 2011 dan telah melayani 5.425 SR dari pelanggan aktif pada tahun 2015. Tujuan dari penelitian ini adalah mengevaluasi kinerja eksisting dan memprediksi kinerja kuantitatif, terutama debit masukan di IPAL Mojosongo, berdasarkan proyeksi pertumbuhan jumlah penduduk dan jumlah pelanggan air limbah di wilayah pelayanan dalam jangka waktu 20 tahun mendatang. Alternatif pengembangan pengolahan air limbah juga diberikan sebagai salah satu solusi jangka panjang dalam konsep pengolahan air limbah rumah tangga di Kota Surakarta. Hasil analisis penelitian menunjukkan bahwa kinerja eksisting IPAL Mojosongo dari segi kuantitatif berdasarkan debit air limbah yang mengalir dari $5.425 \mathrm{SR}$ adalah $31 \mathrm{~L} /$ detik, sedangkan dari segi kualitatif berdasarkan nilai efisiensi pengolahan hasil uji kualitas air limbah adalah 71,31\% efisiensi $\mathrm{BOD}_{5}$ dan 60,83\% efisiensi COD. Prediksi kinerja kuantitatif debit masukan IPAL Mojosongo dalam 20 tahun mendatang berdasarkan jumlah penduduk sebesar $149 \mathrm{~L} /$ detik dan berdasarkan jumlah pelanggan sebesar $50 \mathrm{~L} /$ detik. Alternatif pengembangan pengolahan air limbah sebagai solusi jangka panjang difokuskan pada pengolahan utama IPAL, yaitu unit aerasi, dengan melakukan perubahan waktu tinggal, perubahan alur sistem pengolahan secara paralel, dan peningkatan jumlah penggunaan aerator.
\end{abstract}

Kata kunci : Mojosongo, IPAL, debit, jumlah penduduk, jumlah pelanggan

\section{PENDAHULUAN}

Pengolahan air limbah rumah tangga atau domestik untuk Kota Surakarta telah ditetapkan dalam SP Walikota Surakarta No.800/646 Tahun 1998 dan Perda Kota Surakarta No.3 Tahun 1999 tentang Pengolahan Limbah Cair. Salah satu konsep pengelolaan air limbah domestik sistem perpipaan (offsite) adalah IPAL Mojosongo. Fakta mengenai peningkatan jumlah penduduk di wilayah pelayanan IPAL dan jumlah pelanggan IPAL yang terjadi setiap tahunnya dapat berbanding lurus dengan peningkatan jumlah produksi air limbah domestik dalam 20 tahun mendatang. Hal ini akan berpengaruh terhadap kinerja kuantitatif dan kinerja kualitatif dari IPAL Mojosongo. 


\section{TINJAUAN PUSTAKA}

Tomy Mahendra Yuri Asmoro (2010) dalam penelitiannya menyimpulkan bahwa hasil analisis kualitas limbah cair meliputi $\mathrm{pH}, \mathrm{BOD}$ efluen, TSS efluen, serta efisiensi dari BOD dan TSS menunjukkan bahwa sistem pengolahan di IPAL Mojosongo telah berlangsung baik.

Oktabrina Adithia Syukma (2010) dalam penelitiannya menyimpulkan bahwa kualitas limbah cair di IPAL Mojosongo setelah dilakukan pengujian masih memenuhi standar, namun IPAL Mojosongo diprediksi tidak mampu menampung dan mengolah limbah cair pada tahun 2020.

Vina Arkedina (2013) dalam penelitiannya menyimpulkan bahwa proses pengolahan limbah rumah tangga oleh IPAL Mojosongo telah dilaksanakan sesuai dengan UU No.32/2009, Perda Jawa Tengah No.5/2012, dan Perda Surakarta No.3/1999.

\section{LANDASAN TEORI}

\section{Air Limbah}

Definisi limbah menurut UU No.13/2010 tentang Pengelolaan Lingkungan Hidup adalah sisa usaha dan/atau kegiatan. Limbah pada dasarnya berarti suatu bahan yang terbuang atau dibuang dari suatu sumber hasil aktivitas manusia dan proses-proses alam yang tidak atau belum mempunyai nilai ekonomi atau bahkan dapat mempunyai nilai ekonomi yang negatif.

\section{Sumber Air Limbah}

Sugiharto (2008) membedakan sumber air limbah menjadi 3 kelompok, yaitu :

1. Air limbah rumah tangga (domestik), yang berasal dari perumahan, perdangan, kelembagaan, dan rekreasi.

2. Air limbah industri, yang bergantung dari jenis dan besar-kecilnya industri, pengawasan pada proses industri, serta derajat penggunaan air dan pengolahan limbah yang ada.

3. Air limbah limpasan dan rembesan air hujan yang meresap ke dalam tanah secara bersamaan sebagai akibat terjadinya hujan.

\section{Karakteristik Air Limbah}

Penentuan karakteristik air limbah perlu diketahui 3 jenis sifatnya terlebih dahulu, yaitu :

1. Sifat fisika, ditentukan berdasarkan bau, warna, temperatur, dan kandungan zat padat sebagai efek estetika dari kejernihan.

2. Sifat kimia, ditentukan berdasarkan kandungan derajat keasaman $(\mathrm{pH})$, kebutuhan oksigen biokimiawi (BOD), kebutuhan oksigen kimiawi (COD), dan oksigen terlarut (DO) di dalam air limbah yang dapat merugikan lingkungan.

3. Sifat biologi, ditentukan berdasarkan jenis mikroorganisme yang terkandung dalam air limbah yang efisiensi untuk proses biologis dan evaluasi kualitas air.

\section{Baku Mutu Air Limbah}

Syarat baku mutu air limbah domestik berdasarkan Perda Jawa Tengah No.5/2012 ditampilkan pada Tabel 1 berikut.

Tabel 1. Baku Mutu Air Limbah Domestik

\begin{tabular}{clc}
\hline No. & \multicolumn{1}{c}{ Parameter } & Kadar Maksimum \\
\hline 1 & BOD & $100 \mathrm{mg} / \mathrm{L}$ \\
\hline 2 & TSS & $100 \mathrm{mg} / \mathrm{L}$ \\
\hline 3 & Minyak dan Lemak & $10 \mathrm{mg} / \mathrm{L}$ \\
\hline 4 & $\mathrm{pH}$ & $6,0-9,0$ \\
\hline
\end{tabular}

\section{Instalasi Pengolah Air Limbah (IPAL)}

Instalasi pengolah air limbah (IPAL) berdasarkan Peraturan Menteri Lingkungan Hidup No.112/2003 adalah suatu sistem pengolahan air limbah yang melakukan pengolahan terhadap air limbah domestik sehingga mutu air limbah 
yang dibuang ke lingkungan tidak melampaui baku mutu air limbah domestik yang telah ditetapkan dan membuat saluran pembuangan air limbah domestik tertutup dan kedap air agar tidak terjadi perembesan air limbah ke lingkungan.

\section{Pengolahan Air Limbah}

Kegiatan pengolahan air limbah secara garis besar dikelompokkan menjadi 5 bagian, yaitu:

1. Pengolahan awal (pre treatment), melibatkan proses fisik yang bertujuan menghilangkan zat padat dalam aliran air limbah.

2. Pengolahan tahap pertama (primary treatment), bertujuan untuk menghilangkan zat padat tercampur melalui pengendapan dan pengapungan.

3. Pengolahan tahap kedua (secondary treatment), mencakup proses biologis untuk mengurangi bahan-bahan organik melalui mikroorganisme yang ada di dalam air limbah.

4. Pengolahan tahap ketiga (tertiary treatment), dipergunakan sebagai kelanjutan dari pengolahan sebelumnya jika masih banyak terdapat zat tertentu yang berbahaya.

5. Pengolahan lumpur (sludge treatment), khusus mengolah lumpur yang terbentuk sebagai hasil dari pengolahan sebelumnya.

\section{Kolam Fakultatif}

Kolam fakultatif merupakan kolam yang terjadi proses biodegradasi secara aerobik (terjadi pada permukaan sampai pada $3 / 4$ kedalaman kolam) dan biodegradasi anaerobik (terjadi pada lumpur di dasar kolam sampai $1 / 4$ kedalaman kolam). Kolam fakultatif berfungsi sebagai bioreaktor alami tanpa resirkulasi lumpur aktif. Diagram kolam fakultatif ditunjukkan pada Gambar 1 berikut.

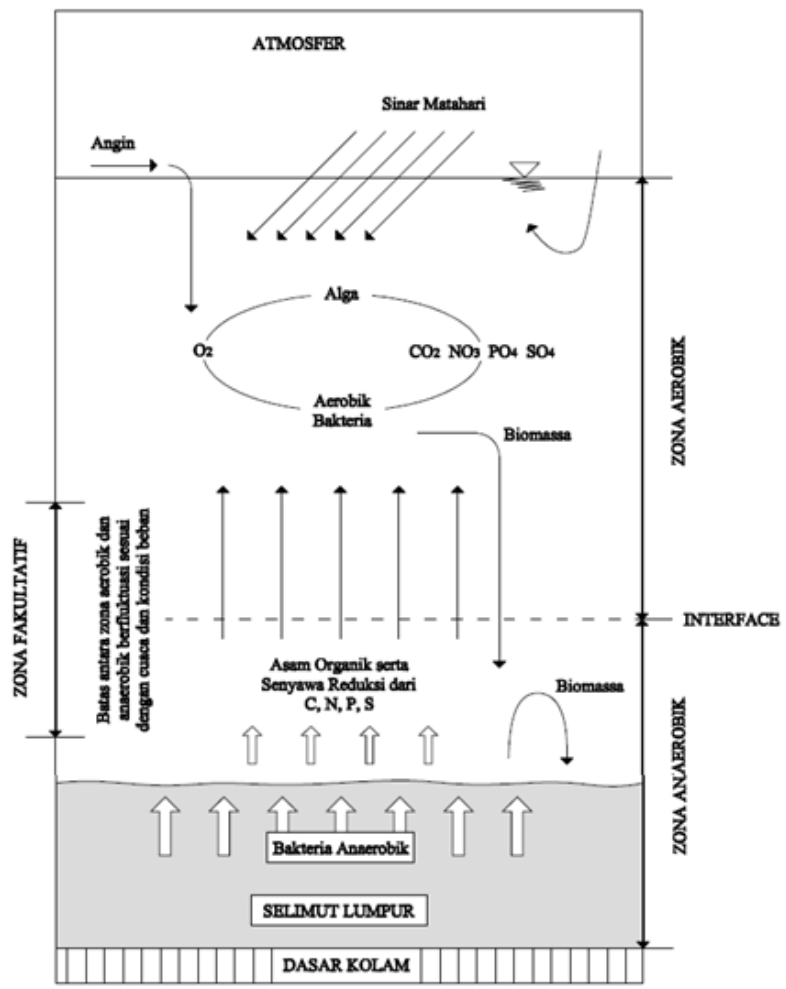

Gambar 1. Sistem Biologi Kolam Fakultatif

Langkah perhitungan untuk perencanaan kolam fakultatif antara lain :

1. Perhitungan nilai $\mathrm{k}_{\mathrm{f}}$ berdasarkan suhu dengan Persamaan 1 berikut.

$\mathrm{k}_{\mathrm{f}}=0,3 \cdot(1,05)^{\mathrm{T}-20}$

Keterangan :

$\mathrm{k}_{\mathrm{f}}=$ tingkat reaksi orde pertama aliran tercampur kolam fakultatif (hari-1 ${ }^{-1}$

$\mathrm{T}=$ temperatur $\left({ }^{\circ} \mathrm{C}\right)$ 
2. Perhitungan waktu tinggal hidrolik kolam berdasarkan efisiensi BOD dengan Persamaan 2 berikut.

$\frac{\mathrm{L}_{\mathrm{e}}}{\mathrm{L}_{\mathrm{i}}}=\frac{1}{1+\mathrm{k}_{\mathrm{f}} \cdot \mathrm{t}_{\mathrm{f}}}$

Keterangan :

$\mathrm{L}_{\mathrm{e}}=\mathrm{BOD}$ efluen $(\mathrm{mg} / \mathrm{L})$

$\mathrm{L}_{\mathrm{i}}=\mathrm{BOD}$ influen $(\mathrm{mg} / \mathrm{L})$

$\mathrm{k}_{\mathrm{f}}=$ tingkat reaksi orde pertama aliran tercampur kolam fakultatif (hari- ${ }^{-1}$ )

$\mathrm{t}_{\mathrm{f}}=$ waktu tinggal hidrolik kolam fakultatif (hari)

3. Penetapan kedalaman kolam fakultatif.

4. Perhitungan kebutuhan lahan kolam fakultatif dengan Persamaan 3 berikut.

$A_{\mathrm{f}}=\frac{\text { Q.t. }}{\mathrm{H}}$

Keterangan :

$\mathrm{A}_{\mathrm{f}}=$ luas kolam fakultatif $\left(\mathrm{m}^{2}\right)$

$\mathrm{Q}=$ debit aliran air limbah $\left(\mathrm{m}^{3} /\right.$ hari)

$\mathrm{t}_{\mathrm{f}}=$ waktu tinggal hidrolik kolam fakultatif (hari)

$\mathrm{H}=$ kedalaman $\operatorname{kolam}(\mathrm{m})$

5. Pemilihan nilai waktu tinggal hidrolik dan perhitungan ulang kebutuhan lahan kolam secara seri dengan Persamaan 4 berikut.

$\frac{\mathrm{L}_{\mathrm{e}}}{\mathrm{L}_{\mathrm{i}}}=\left[\frac{1}{1+\mathrm{k}_{\mathrm{f}} \cdot \mathrm{t}_{\mathrm{f}}}\right]^{\mathrm{n}}$

Keterangan :

$\mathrm{L}_{\mathrm{e}}=\mathrm{BOD}$ efluen $(\mathrm{mg} / \mathrm{L})$

$\mathrm{L}_{\mathrm{i}}=\mathrm{BOD}$ influen $(\mathrm{mg} / \mathrm{L})$

$\mathrm{k}_{\mathrm{f}}=$ tingkat reaksi orde pertama aliran tercampur kolam fakultatif $\left(\right.$ hari $\left.{ }^{-1}\right)$

$\mathrm{t}_{\mathrm{f}}=$ waktu tinggal hidrolik kolam fakultatif (hari)

$\mathrm{n}=$ jumlah kolam fakultatif dalam rangkaian seri

\section{Efisiensi Pengolahan}

Skala efisiensi yang ingin dicapai dari suatu kegiatan atau aktivitas diberikan berdasarkan pada kriteria-kriteria yang telah ditetapkan. Dalam hal sistem pengolahan di IPAL, efisiensi biasanya diberikan dalam kriteria desain pengolahan yang digunakan. Nilai efisiensi pengolahan air limbah, terutama BOD 5 dan COD, dihitung pada Persamaan 5 berikut. Eff. $=\frac{\mathrm{C}_{\mathrm{i}}-\mathrm{C}_{\mathrm{e}}}{\mathrm{C}_{\mathrm{i}}} \times 100 \%$

Keterangan :

Eff. = nilai efisiensi $(\%)$

$\mathrm{C}_{\mathrm{i}}=$ konsentrasi influen $(\mathrm{mg} / \mathrm{L})$

$\mathrm{C}_{\mathrm{e}}=$ konsentrasi efluen $(\mathrm{mg} / \mathrm{L})$

\section{Proyeksi Jumlah Penduduk}

Metode proyeksi jumlah penduduk yang digunakan adalah metode geometrik dengan Persamaan 6 dan 7 berikut.

$\mathrm{Pn}=\mathrm{Po}(1+\mathrm{r})^{\mathrm{n}}$

$\mathrm{r}=\frac{\text { jumlah } \% \text { pertambahan }}{\operatorname{tahun}_{\mathrm{n}}-\text { tahun }_{\mathrm{o}}}$

Keterangan :

Pn $=$ jumlah penduduk pada tahun ke-n

Po $=$ jumlah penduduk pada tahun awal

$\mathrm{r}=$ angka pertumbuhan penduduk per tahun $(\%)$

$\mathrm{n}$ = waktu periode proyeksi (tahun)

\section{Debit Air Limbah}


Penetuan debit air limbah diperoleh berdasarkan besarnya pemakaian air bersih dengan memperhitungkan faktor timbulan air buangan dihitung pada Persamaan 8 dan 9 berikut.

$\mathrm{Q}_{\mathrm{al}}=\mathrm{f}_{\mathrm{ab}} \times \mathrm{Q}_{\mathrm{ab}}$

(Sumber: Metcalf \& Eddy, 1991)

$\mathrm{Q}_{\mathrm{ab}}=80 \% \times \mathrm{q} \times\left(\mathrm{P} \times \mathrm{K}_{\mathrm{a}}\right)$

(Sumber: Dirjen Cipta Karya, 1996)

Keterangan :

$\mathrm{Q}_{\mathrm{al}}=$ debit air limbah $(\mathrm{L} /$ hari)

$\mathrm{f}_{\mathrm{ab}}=$ faktor timbulan air buangan $(60 \%-85 \%)$

$\mathrm{Q}_{\mathrm{ab}}=$ kebutuhan air bersih (L/hari)

$\mathrm{K}_{\mathrm{a}}=$ tingkat kebutuhan air (\%) (Tabel 2)

$\mathrm{q} \quad=$ konsumsi rata-rata air bersih (L/jiwa/hari)

$\mathrm{P} \quad=$ jumlah pemakai (jiwa)

\section{METODE PENELITIAN}

Metode yang digunakan dalam penelitian ini adalah deskriptif kuantitatif dan evaluatif. Metode ini berupa pengumpulan data, analisis data, dan pembahasan hasil analisis untuk pengambilan keputusan.

\section{Lokasi Penelitian}

Penelitian dilakukan di IPAL Kedung Tungkul Mojosongo yang berlokasi di Kelurahan Mojosongo, Kota Surakarta ditunjukkan pada Gambar 2 berikut.

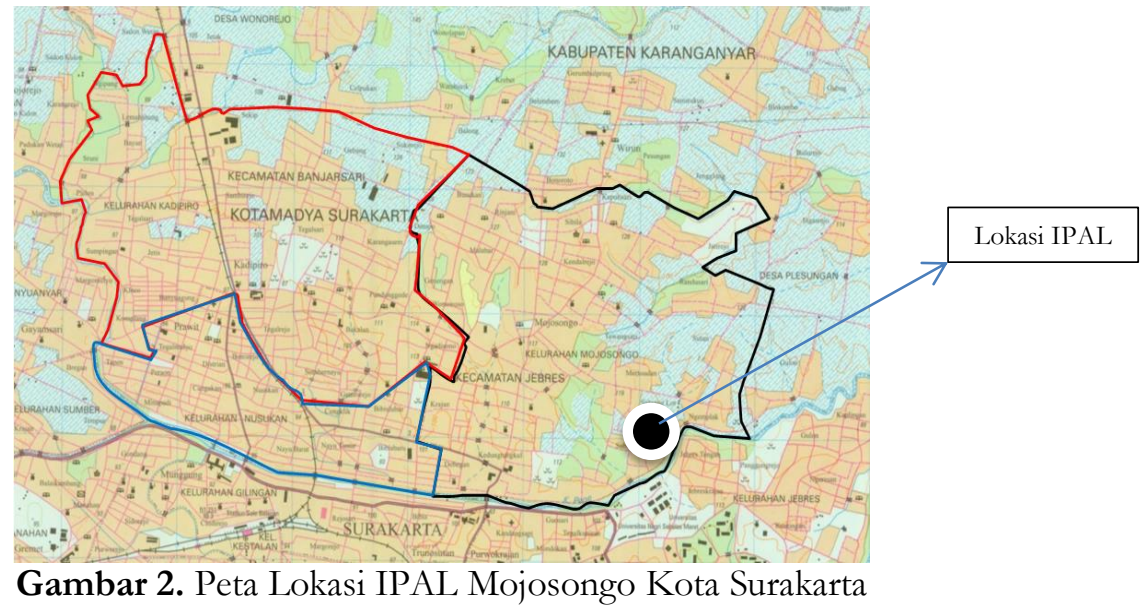

\section{HASIL DAN PEMBAHASAN}

\section{Gambaran Umum IPAL Mojosongo}

Unit-unit pengolah di IPAL Mojosongo terdiri dari sumur pengumpul dengan pompa (sump pump), bak pengendap awal, bak aerasi I (aerated lagoon I), bak aerasi II (aerated lagoon II), bak sedimentasi (sedimentation pond), dan bak pengering lumpur (sludge drying bed). Rekapitulasi hasil perhitungan volume unit-unit di IPAL Mojosongo ditampilkan pada Tabel 2 berikut.

Tabel 2. Rekapitulasi Hasil Perhitungan Volume Unit IPAL Mojosongo

\begin{tabular}{clc}
\hline No & \multicolumn{1}{c}{ Unit Pengolah } & Volume $\mathbf{( m}^{\mathbf{3}} \mathbf{)}$ \\
\hline 1 & Sumur Pengumpul & 53,46 \\
\hline 2 & Bak Pengendap Awal & 222,32 \\
\hline 3 & Bak Aerasi I & $5.308,625$ \\
\hline
\end{tabular}




\begin{tabular}{clc}
\hline 4 & Bak Aerasi II & $5.097,75$ \\
\hline 5 & Bak Sedimentasi & $7.698,219$ \\
\hline 6 & Bak Pengering Lumpur & 1.536 \\
\hline
\end{tabular}

\section{Kondisi Eksisting Kuantitatif IPAL Mojosongo}

Kapasitas (debit) air limbah eksisting yang mengalir menuju IPAL Mojosongo berdasarkan hasil analisis dari 5.425 sambungan rumah adalah $31 \mathrm{~L} /$ detik. Hasil ini menunjukkan bahwa IPAL Mojosongo masih mampu mengolah air limbah yang dihasilkan oleh pelanggan IPAL saat ini karena debit air limbah yang dihasilkan tidak melebihi batas kapasitas terpasang (kapasitas desain) tampungan IPAL, yaitu sebesar $50 \mathrm{~L} /$ detik $\left(\mathrm{Q}_{\text {IPAL }}>\mathrm{Q}_{\mathrm{al}}\right)$.

\section{Kondisi Eksisting Kualitatif IPAL Mojosongo}

Kondisi eksisting kualitas pengolahan IPAL Mojosongo berdasarkan hasil analisis dari rerata hasil uji air limbah (data oleh pihak IPAL Mojosongo) diperoleh bahwa nilai efisiensi $\mathrm{BOD}_{5}$ adalah 71,31\% dan nilai efisiensi COD adalah 60,83\%. Hasil ini menyatakan bahwa keseluruhan pengolahan air limbah di IPAL Mojosongo saat ini berlangsung dengan baik karena nilai efisiensi yang dihasilkan berada di atas 50\%.

\section{Penetuan Debit Air Limbah dari Proyeksi Jumlah Penduduk}

Rekapitulasi hasil perhitungan kebutuhan air bersih dan debit air limbah yang dihasilkan berdasarkan proyeksi jumlah penduduk di wilayah pelayanan IPAL Mojosongo mulai tahun 2016 - 2035 ditampilkan pada Tabel 3 berikut.

Tabel 3. Rekapitulasi Hasil Debit Air Limbah yang Dihasilkan dari Penduduk

\begin{tabular}{cccc}
\hline Tahun & $\mathbf{P}_{\mathbf{n}}$ (jiwa) & $\mathbf{Q}_{\mathbf{a b}}(\mathbf{L} /$ detik) & $\mathbf{Q}_{\text {al }}(\mathbf{L} /$ detik $)$ \\
\hline 2016 & $140.879,76$ & 125,27 & 100,18 \\
\hline 2017 & $143.839,42$ & 127,86 & 102,29 \\
\hline 2018 & $146.861,25$ & 130,54 & 104,43 \\
\hline 2019 & $149.946,57$ & 133,29 & 106,63 \\
\hline 2020 & $153.096,70$ & 136,09 & 108,87 \\
\hline 2021 & $156.313,02$ & 138,94 & 111,16 \\
\hline 2022 & $159.596,90$ & 141,86 & 113,49 \\
\hline 2023 & $162.949,78$ & 144,84 & 115,88 \\
\hline 2024 & $166.373,09$ & 147,89 & 118,31 \\
\hline 2025 & $169.868,32$ & 150,99 & 120,80 \\
\hline 2026 & $173.436,98$ & 154,17 & 123,33 \\
\hline 2027 & $177.080,61$ & 157,40 & 125,92 \\
\hline 2028 & $180.800,79$ & 160,71 & 128,57 \\
\hline 2029 & $184.599,12$ & 164,09 & 131,27 \\
\hline 2030 & $188.477,25$ & 167,54 & 134,03 \\
\hline 2031 & $192.436,85$ & 171,05 & 136,84 \\
\hline 2032 & $196.479,64$ & 174,65 & 139,72 \\
\hline 2033 & $200.607,36$ & 178,32 & 142,65 \\
\hline 2034 & $204.821,80$ & 182,06 & 145,65 \\
\hline 2035 & $209.124,78$ & 185,89 & 148,71 \\
\hline
\end{tabular}

Tabel 3 menunjukkan bahwa IPAL Mojosongo tidak mampu mengolah air limbah yang dihasilkan oleh seluruh penduduk di wilayah pelayanan IPAL karena debit air limbah yang dihasilkan adalah sebesar 148,71 L/detik atau dapat dinyatakan melebihi batas kapasitas tampungan IPAL sebesar $50 \mathrm{~L} /$ detik ( $\mathrm{Q}_{\mathrm{AL}}>\mathrm{Q}_{\mathrm{IPAL}}$ ).

\section{Penetuan Debit Air Limbah dari Proyeksi Jumlah Pelanggan}

Rekapitulasi hasil perhitungan kebutuhan air bersih dan debit air limbah yang dihasilkan berdasarkan proyeksi jumlah pelanggan IPAL Mojosongo mulai tahun 2016 - 2035 ditampilkan pada Tabel 4 berikut. 
Tabel 4. Rekapitulasi Hasil Debit Air Limbah yang Dihasilkan dari Pelanggan

\begin{tabular}{ccccc}
\hline Tahun & $\left.\mathbf{P l}_{\mathbf{n}} \mathbf{( S R}\right)$ & $\mathbf{P l}_{\mathbf{n}}(\mathbf{j i w a})$ & $\mathbf{Q}_{\text {ab }}(\mathbf{L} /$ detik) & $\mathbf{Q}_{\mathbf{a l}}(\mathbf{L} /$ detik) \\
\hline 2016 & $5.561,04$ & 27805,21 & 38,62 & 30,89 \\
\hline 2017 & $5.700,50$ & 28502,49 & 39,59 & 31,67 \\
\hline 2018 & $5.843,45$ & 29217,24 & 40,58 & 32,46 \\
\hline 2019 & $5.989,98$ & 29949,93 & 41,60 & 33,28 \\
\hline 2020 & $6.140,20$ & 30700,98 & 42,64 & 34,11 \\
\hline 2021 & $6.294,17$ & 31470,87 & 43,71 & 34,97 \\
\hline 2022 & $6.452,01$ & 32260,06 & 44,81 & 35,84 \\
\hline 2023 & $6.613,81$ & 33069,05 & 45,93 & 36,74 \\
\hline 2024 & $6.779,66$ & 33898,32 & 47,08 & 37,66 \\
\hline 2025 & $6.949,68$ & 34748,39 & 48,26 & 38,61 \\
\hline 2026 & $7.123,96$ & 35619,78 & 49,47 & 39,58 \\
\hline 2027 & $7.302,60$ & 36513,02 & 50,71 & 40,57 \\
\hline 2028 & $7.485,73$ & 37428,65 & 51,98 & 41,59 \\
\hline 2029 & $7.673,45$ & 38367,25 & 53,29 & 42,63 \\
\hline 2030 & $7.865,88$ & 39329,39 & 54,62 & 43,70 \\
\hline 2031 & $8.063,13$ & 40315,65 & 55,99 & 44,80 \\
\hline 2032 & $8.265,33$ & 41326,65 & 57,40 & 45,92 \\
\hline 2033 & $8.472,60$ & 42363 & 58,84 & 47,07 \\
\hline 2034 & $8.685,07$ & 43425,33 & 60,31 & 48,25 \\
\hline 2035 & $8.902,86$ & 44514,31 & 61,83 & 49,46 \\
\hline
\end{tabular}

Tabel 4 menunjukkan bahwa IPAL Mojosongo masih mampu mengolah air limbah yang hanya dihasilkan oleh pelanggan IPAL karena debit air limbah yang dihasilkan adalah sebesar 49,46 L/detik atau dapat dinyatakan hampir mendekati sama dengan batas kapasitas tampungan IPAL sebesar $50 \mathrm{~L} /$ detik $\left(\mathrm{Q}_{\mathrm{AL}} \approx \mathrm{Q}_{\mathrm{IPAL}}\right)$.

\section{Efisiensi dan Kapasitas Pengolahan Unit Aerasi IPAL Mojosongo}

Efisiensi dan kapasitas pengolahan unit aerasi dianalisis berdasarkan rerata hasil uji sampel air limbah di titik inlet dan titik outlet dari masing-masing unit aerasi seperti ditunjukkan pada Gambar 3 berikut.

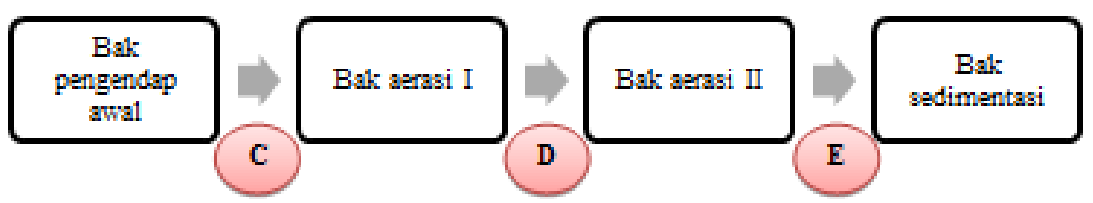

Gambar 3. Titik Inlet dan Titik Outlet Masing-Masing Unit Aerasi

Rekapitulasi hasil perhitungan efisiensi dan kapasitas pada unit aerasi IPAL Mojosongo ditampilkan pada Tabel 5 berikut.

Tabel 5. Rekapitulasi Hasil Perhitungan Efisiensi dan Kapasitas Unit Aerasi

\begin{tabular}{ccccc}
\hline Unit & $\begin{array}{c}\text { Volume } \\
\left(\mathbf{m}^{3}\right)\end{array}$ & $\begin{array}{c}\text { Efisiensi } \\
\text { BOD }_{\mathbf{5}}\end{array}$ & $\begin{array}{c}\text { Waktu } \\
\text { Tinggal (jam) }\end{array}$ & $\begin{array}{c}\text { Kapasitas } \\
(\mathbf{L} / \text { detik) }\end{array}$ \\
\hline Bak Aerasi I & $5.308,625$ & $28,23 \%$ & 20,4 & 72,3 \\
\hline Bak Aerasi II & $5.097,75$ & $53,60 \%$ & 60 & 23,65 \\
\hline
\end{tabular}




\section{ALTERNATIF PENGEMBANGAN PENGOLAHAN IPAL MOJOSONGO}

Alternatif Perubahan Waktu Tinggal pada Unit Aerasi

Nilai waktu tinggal yang terjadi akan mempengaruhi kapasitas masing-masing unit aerasi, sehingga diberikan beberapa alternatif seperti ditampilkan pada Tabel 6 berikut.

Tabel 6. Rekapitulasi Hasil Perhitungan Perubahan Waktu Tinggal Unit Aerasi

\begin{tabular}{cccccccccc}
\hline \multirow{2}{*}{ Unit } & $\begin{array}{c}\text { Volume } \\
\end{array}$ & $\left.\mathbf{( m}^{\mathbf{3}}\right)$ & \multicolumn{3}{c}{ Waktu Tinggal (jam) } & \multicolumn{4}{c}{ Kapasitas (L/detik) } \\
\cline { 2 - 24 } & I & II & III & IV & I & II & III & IV \\
\hline Bak Aerasi I & $5.308,625$ & 120 & 60 & 45 & 23 & 12,29 & 24,58 & 32,77 & 64,11 \\
\hline Bak Aerasi II & $5.097,75$ & 120 & 60 & 45 & 23 & 11,8 & 23,6 & 31,47 & 61,57 \\
\hline
\end{tabular}

Tabel 6 menunjukkan bahwa kapasitas dari alternatif waktu tinggal keempat $(\mathrm{tf}=23 \mathrm{jam})$ dipilih karena hasil tersebut menyatakan bahwa IPAL Mojosongo masih mampu mengolah debit air limbah yang hanya dihasilkan oleh pelanggan IPAL saja, sedangkan debit air limbah yang berasal dari seluruh penduduk di wilayah pelayanan IPAL tidak akan mampu untuk diolah dalam 20 tahun mendatang, sehingga alternatif lanjutan pun dibutuhkan guna memberikan solusi atas kondisi tersebut.

\section{Alternatif Perubahan Alur Sistem Pengolahan pada Unit Aerasi}

Alur sistem pengolahan IPAL Mojosongo yang saat ini berlangsung seri direncanakan untuk diubah ke sistem paralel, terutama pada unit aerasi. Bagan perubahan alur sistem menjadi paralel ditunjukkan pada Gambar 4 berikut.

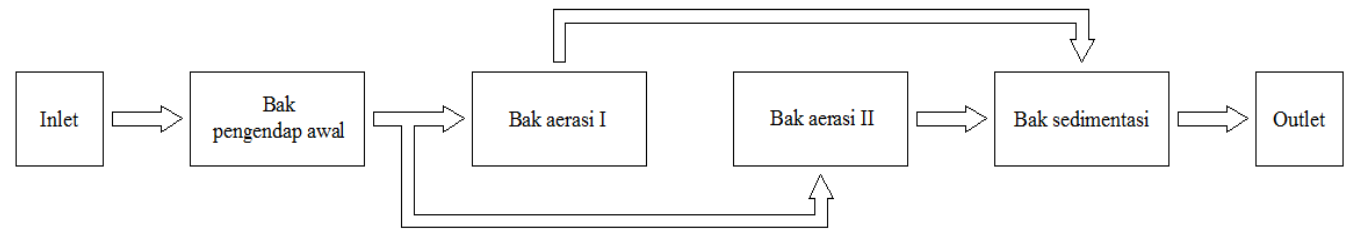

Gambar 4. Alur Sistem Pengolahan Unit Aerasi secara Paralel

Nilai kapasitas yang diperoleh dari alternatif keempat pada Tabel 6 untuk masing-masing unit aerasi adalah 60 L/detik. Nilai kapasitas tersebut dapat meningkat menjadi dua kali lipat menjadi $120 \mathrm{~L} /$ detik jika alur sistem pengolahan pada unit aerasi diubah ke sistem paralel seperti yang ditunjukkan pada Gambar 4. Perwujudan kondisi tersebut dimungkinkan akan tercapai jika dilakukan alternatif lanjutan mengenai pelayanan air limbah oleh IPAL Mojosongo.

\section{Alternatif Peningkatan Kualitas Pengolahan pada Unit Aerasi}

Waktu tinggal yang terjadi pada unit aerasi tidak hanya berpengaruh terhadap kapasitas unit, tetapi juga berpengaruh terhadap efisiensi pengolahan seperti ditampilkan pada Tabel 7 berikut.

Tabel 7. Rekapitulasi Hasil Perhitungan Efisiensi dan $\mathrm{BOD}_{5}$ Unit Aerasi

\begin{tabular}{|c|c|c|c|c|}
\hline Unit & $\begin{array}{c}\text { Volume } \\
\left(\mathrm{m}^{3}\right)\end{array}$ & $\begin{array}{c}\text { Waktu } \\
\text { Tinggal (jam) }\end{array}$ & $\begin{array}{l}\text { Kapasitas } \\
\text { (L/detik) }\end{array}$ & $\begin{array}{c}\text { Efisiensi } \\
\text { BOD }_{5}\end{array}$ \\
\hline Bak Aerasi I & $5.308,625$ & 23 & 64,11 & $30,73 \%$ \\
\hline Bak Aerasi II & $5.097,75$ & 23 & 61,57 & $30,73 \%$ \\
\hline
\end{tabular}

Tabel 7 menunjukkan bahwa unit aerasi yang mengalami percepatan waktu tinggal akan memiliki nilai efisiensi yang jauh lebih rendah. Jika nilai efisiensi ini dibandingkan dengan nilai efisiensi sebelumnya (lihat Tabel 6), maka dapat diperkirakan bahwa hal tersebut terjadi karena adanya perbedaan pelaksanaan operasi, yaitu perbedaan pada jumlah penggunaan aerator. Oleh karena itu, jumlah penggunaan aerator dapat ditingkatkan agar efisiensi yang diinginkan dapat tercapai. 


\section{Alternatif Pelayanan Air Limbah di IPAL Mojosongo}

IPAL Mojosongo dapat melakukan pelayanan pengolahan air limbah untuk penduduk di wilayah pelayanannya dengan berdasarkan Lampiran Kepmen Nomor 534/KPTS/M/2001 tentang Pedoman Penentuan Standar Pelayanan Minimal (SPM) untuk bidang pelayanan air limbah yang memberikan standar pelayanan dengan kuantitas mencakup 80\% dari jumlah penduduk kota. Dengan kata lain, hal ini dapat diartikan bahwa hanya 80\% jumlah penduduk total di wilayah pelayanan IPAL yang akan mengalirkan air limbahnya ke IPAL Mojosongo dalam 20 tahun mendatang, sehingga rekapitulasi hasil debit air limbah yang dihasilkan berdasarkan SPM ditampilkan pada Tabel 8 berikut.

Tabel 8. Rekapitulasi Hasil Debit Air Limbah berdasarkan Standar Pelayanan Minimal (SPM)

\begin{tabular}{ccccc}
\hline Tahun & $\mathbf{P}_{\mathbf{n}}$ (jiwa) & $\mathbf{8 0} \mathbf{\% . P}_{\mathbf{n}}$ (jiwa) & $\mathbf{Q}_{\mathbf{a b}}(\mathbf{L} /$ detik) & $\mathbf{Q}_{\mathbf{a l}}(\mathbf{L} /$ detik) \\
\hline 2016 & $140.879,76$ & $112.703,81$ & 100,18 & 80,14 \\
\hline 2017 & $143.839,42$ & $115.071,53$ & 102,29 & 81,83 \\
\hline 2018 & $146.861,25$ & 117.489 & 104,43 & 83,55 \\
\hline 2019 & $149.946,57$ & $119.957,25$ & 106,63 & 85,30 \\
\hline 2020 & $153.096,70$ & $122.477,36$ & 108,87 & 87,10 \\
\hline 2021 & $156.313,02$ & $125.050,41$ & 111,16 & 88,92 \\
\hline 2022 & $159.596,90$ & $127.677,52$ & 113,49 & 90,79 \\
\hline 2023 & $162.949,78$ & $130.359,82$ & 115,88 & 92,70 \\
\hline 2024 & $166.373,09$ & $133.098,47$ & 118,31 & 94,65 \\
\hline 2025 & $169.868,32$ & $135.894,66$ & 120,80 & 96,64 \\
\hline 2026 & $173.436,98$ & $138.749,58$ & 123,33 & 98,67 \\
\hline 2027 & $177.080,61$ & $141.664,49$ & 125,92 & 100,74 \\
\hline 2028 & $180.800,79$ & $144.640,63$ & 128,57 & 102,86 \\
\hline 2029 & $184.599,12$ & $147.679,30$ & 131,27 & 105,02 \\
\hline 2030 & $188.477,25$ & $150.781,80$ & 134,03 & 107,22 \\
\hline 2031 & $192.436,85$ & $153.949,48$ & 136,84 & 109,48 \\
\hline 2032 & $196.479,64$ & $157.183,71$ & 139,72 & 111,78 \\
\hline 2033 & $200.607,36$ & $160.485,89$ & 142,65 & 114,12 \\
\hline 2034 & $204.821,80$ & $163.857,44$ & 145,65 & 116,52 \\
\hline 2035 & $209.124,78$ & $167.299,82$ & 148,71 & 118,97 \\
\hline
\end{tabular}

Tabel 8 menunjukkan bahwa debit air limbah yang dihasilkan berdasarkan SPM mencapai $119 \mathrm{~L} /$ detik dan hasil ini menyatakan bahwa debit air limbah yang dihasilkan oleh penduduk di wilayah pelayanan IPAL Mojosongo tidak melebihi batas kapasitas IPAL dari hasil alternatif sebelumnya sebesar $120 \mathrm{~L} /$ detik ( $\left.\mathrm{Q}_{\mathrm{AL}}<\mathrm{Q}_{\mathrm{IPAL}}\right)$.

\section{SIMPULAN}

1. Hasil evaluasi kinerja kuantitatif eksisting IPAL Mojosongo diperoleh sebesar $31 \mathrm{~L} /$ detik, sedangkan hasil evaluasi kinerja kualitatif eksistingnya diperoleh nilai efisiensi $\mathrm{BOD}_{5}$ sebesar $71,31 \%$ dan nilai efisiensi COD sebesar 60,83\%. Hasil tersebut menunjukkan bahwa pengolahan air limbah domestik di IPAL Mojosongo berlangsung dengan baik.

2. Prediksi kinerja kuantitatif IPAL Mojosongo dalam 20 tahun mendatang, yaitu debit air limbah, yang berasal dari penduduk di wilayah pelayanan IPAL adalah $149 \mathrm{~L} /$ detik dari pelanggan IPAL adalah $50 \mathrm{~L} /$ detik.

3. Alternatif pengembangan yang diberikan untuk sistem pengolahan air limbah di IPAL Mojosongo agar tetap mampu melayani penduduk dan pelanggan dalam 20 tahun mendatang dilakukan pada unit aerasi, antara lain melakukan perubahan waktu tinggal (dipercepat) disertai perubahan alur sistem pengolahan secara paralel dengan pelayanan air limbah yang mencakup $80 \%$ dari jumlah penduduk total di wilayah pelayanan IPAL serta peningkatan jumlah penggunaan aerator di unit aerasi agar kualitas pengolahan air limbah dapat menjadi lebih baik.

\section{SARAN}


1. Alternatif pengembangan pengolahan air limbah di IPAL Mojosongo perlu dilakukan untuk menghindari terjadinya kelebihan kapasitas kolam tampungan IPAL dalam 20 tahun mendatang.

2. PDAM Kota Surakarta tetap dapat membangun jaringan perpipaan baru kepada pelanggan di wilayah pelayanan IPAL Mojosongo hingga 20 tahun mendatang apabila melakukan alternatif pengembangan pengolahan IPAL.

3. Perlunya peningkatan dalam pengawasan dan pemantauan terhadap sistem pengolahan air limbah, penggunaan peralatan yang menunjang pengolahan air limbah, dan pemeriksaan kualitas air limbah di IPAL Mojosongo.

4. Penduduk di wilayah pelayanan IPAL Mojosongo diharapkan dapat mengalirkan air limbah domestiknya ke IPAL melalui pemasangan sambungan rumah sebagai bagian dari pengolahan air limbah sistem offsite di Kota Surakarta agar menghindari terjadinya pencemaran air dan tanah akibat air limbah di masa mendatang.

5. Ruang lingkup penelitian selanjutnya dapat diperluas dengan meninjau instalasi pengolah air limbah lainnya di Kota Surakarta sehingga tidak hanya pada satu lingkup penelitian di IPAL Mojosongo saja.

\section{UCAPAN TERIMA KASIH}

Ucapan terima kasih kepada Ir. Budi Utomo, M.T. dan Ir. Sudarto, M.Si. yang telah membimbing dan memberi arahan serta masukan dalam penelitian ini.

\section{REFERENSI}

Arkedina, Vina. 2013. Tinjauan Yuridis Pengelolaan Limbah Rumah Tangga dalam Upaya Pengendalian Pencemaran Limbah Domestik oleh Unit IP AL PD AM Mojosongo di Kota Surakarta. Universitas Sebelas Maret : Surakarta.

Asmoro, Tomy Mahendra Yuri. 2010. Efisiensi Unit Pengolah Limbah Cair Mojosongo PDAM Kota Surakarta. Universitas Sebelas Maret : Surakarta.

Kementerian Pekerjaan Umum. 1996. Kriteria Perencanaan Kebutuban Air Bersib. Direktorat Jenderal Cipta Karya : Jakarta.

Metcalf and Eddy. 1991. Wastewater Engineering : Treatment, Disposal, and Reuse. McGraw-Hill : New York.

Pemerintah Daerah Kota Surakarta. 1999. Peraturan Daerab Kota Surakarta Nomor 3 Tabun 1999 tentang Pengelolaan Limbah Cair. Surakarta.

Pemerintah Provinsi Jawa Tengah. 2012. Peraturan Daerah Provinsi Jawa Tengah Nomor 5 Tabun 2012 tentang Perubahan atas Peraturan Daerah Provinsi Jawa Tengah Nomor 10 Tabun 2004 tentang Baku Mutu Air Limbah. Semarang.

Sugiharto. 2008. Dasar-Dasar Pengelolaan Air Limbah. Universitas Indonesia Press : Jakarta.

Pemerintah Daerah Kota Surakarta. 1998. Surat Perintah Walikota Surakarta Nomor 800/646 Tabun 1998 tentang Pengelolaan Limbah. Surakarta.

Syukma, Oktabrina Adithia. 2010. Analisis Kuantitas dan Kualitas Pengolahan Limbah Cair IPAL Mojosongo Surakarta. Universitas Sebelas Maret : Surakarta.

Sekretariat Negara Republik Indonesia. 2003. Keputusan Menteri Lingkungan Hidup Nomor 112 Tabun 2003 tentang Baku Mutu Air Limbah Domestik. Jakarta.

Sekretariat Negara Republik Indonesia. 2009. Undang-Undang Republik Indonesia Nomor 32 Tahun 2009 tentang Perlindungan dan Pengelolaan Lingkungan Hidup. Jakarta.

Sekretariat Negara Republik Indonesia. 2010. Undang-Undang Republik Indonesia Nomor 13 Tabun 2010 tentang Upaya Pengelolaan dan Pemantauan Lingkungan Hidup. Jakarta. 